\title{
GM rice forges ahead in China amid concerns over illegal planting
}

Recently published results of field trials of genetically modified (GM) rice in China bring the country one step closer to approval of commercial varieties. However, observers warn that without proper regulatory oversight and agricultural management, GM rice cultivation poses a potential environmental time bomb. Compounding those fears, illegal planting of unapproved varieties of GM rice has been reported, despite government attempts to introduce a media blackout.

In its April 29 issue, Science (J. Huang et al., 308, 688-690, 2005) published a study indicating two of the four varieties of pestresistant rice currently undergoing field trials in China have 9\% higher crop yields and allow reduced pesticide use than conventional crops. The two crops under study include stem borer-resistant genetically modified rice GM Xianyou 63 and leaf roller-resistant rice GM II-Youming 86 that contain a Bacillus thuringiensis $(B t)$ toxin gene and the cowpea trypsin inhibitor $(C p T I)$ gene, respectively.

The paper's lead author, Jikun Huang, director of the Center for Chinese Agricultural Policy at the Chinese Academy of Sciences (CAS) in Beijing, hopes that the publication will contribute to the approval of the crop for commercial release. That would make China the first country to approve GM rice (Nat. Biotechnol. 22, 642, 2004). The government has been holding back approvals of new transgenic food crops since 2000, to avoid responsibility, some believe, for any resulting health or environmental problems (Nature 435, 3, 2005).

Fears that resistant insects could emerge, should illegal planting fail to use adequate refuge strategies to reduce selective pressure for resistance or buffer zones to reduce gene outcrossing from GM rice to wild rice varieties, have been further fueled by Greenpeace China in Hong Kong. The group reported on April 13 that GM rice seed has been sold and grown illegally in central China's Hubei province, where some of the field trials took place. Pang Cheung Sze, Greenpeace campaigner says, "At least 950 to 1,200 tons of GM rice entered the food chain after last year's harvest." The level of illegal planting may be exaggerated by activists, it seems likely that bootleg GM rice is already in farmers' fields.

Although scientists working under the remit of the Ministry of Agriculture unanimously refused to comment, other scientists affiliated with the State Environmental Protection Administration (SEPA) and the CAS have confirmed the news. Dayuan Xue, a scientist at Nanjing Institute of Environmental Sciences under the SEPA who heads a program of GM rice environmental impact assessment comments, "I heard some field trials of GM rice in Hubei have been illegally expanded to greatly surpass the official cap of $100 \mathrm{mu}$ [6.7 hectares] for field trials of one variety."

China's Ministry of Agriculture dismissed these claims and promised to investigate the issue but the results of the enquiry are not available. Meanwhile, the local agricultural authorities in Hubei have allegedly punished people responsible for the leak. In May, the potential for negative media coverage was such that the Chinese government banned all media coverage of the GM rice leak until further notice.

Even if a GM rice is legally commercialized, Chinese scientists like Huang admit that China's poor control of agricultural management practices opens the possibility for gene flow from transgenic varieties. Thus far, in the trials, scientists have planted their crops within a buffer zone of 100 meters. It is not yet clear what types of buffer zone or refuge will be implemented if the government decides to go ahead and approve a GM rice variety.

Regulations merely stipulate the need to use safety measures whereas buffer zones are mandatory only for crops deemed to have a high safety risk profile. GM cotton, for instance, has been planted since its approval in 1997 without the use of refuges, according to Yongjun Zhang, a research fellow of the Institute of Plant Protection at the Chinese Academy of Agricultural Sciences in Beijing. He believes that the lack of observable resistance is due to the frequent rotation of crops by Chinese cotton growers.

Unlike the cotton growers, however, China's rice farmers commonly grow rice as a monoculture, indicating that insect resistance management may pose a bigger problem for GM rice. And China's rural economic structure further complicates the scenario, according to Xue. Unlike in the US where big farms dominate, China's arable land is distributed among its 700 million farmers who, on average, have less than 0.1 hectare per capita of arable land in rice-growing areas located mainly in southern provinces. "Farmers may be reluctant to contribute parts of their precious land to refuges if they see the economic benefits of GM rice," says Xue.

Besides resistance, Xue is also concerned about the outcrossing of genes from GM varieties to the three wild races identified so far in China. This could potentially compromise the integrity and natural (perhaps highly valu-

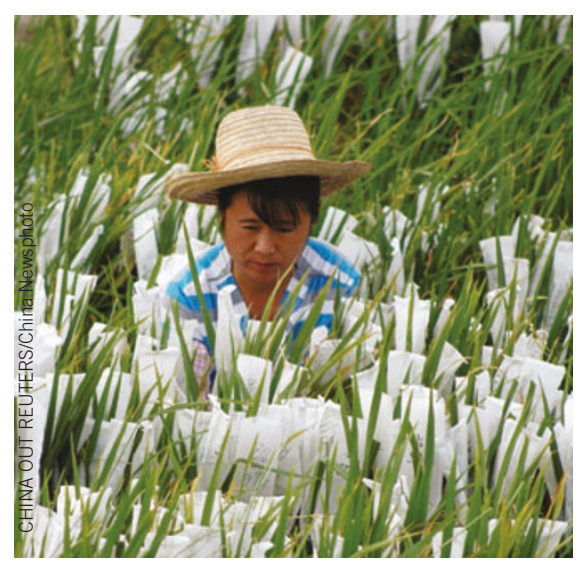

GM rice yields could soon supersede even the highest yielding hybrid rice in China

able) traits of indigenous rice varieties, replaying concerns expressed by environmentalists about $B t$ corn and wild corn and teosinte in Mexico (Nat. Biotechnol. 23, 6, 2005) and Bt rice and basmati rice in India.

Yet for some crop scientists, the environmental hazards of GM rice have been overplayed. Feng Wang, director of Fujian Agricultural Genetic Engineering Laboratory in Fuzhou, says, "In practice, Chinese farmers always plant a diversity of rice seeds instead of one or two varieties," adding "This would help form a 'natural refuge' for GM rice if it is commercialized."

He adds that his unpublished studies of GM rice developed by CAS scientists containing both $B t$ and CPTI genes show that in natural environments, the pollination distance of rice is negligible beyond 10 meters (rather than the previously recognized distance of 100 meters.) "If the result can be widely proved, there will be no need to set up a wide refuge belt for GM rice so that the difficulty and costs of doing so will be largely reduced," says Wang. Yet, pollen movement studies are notoriously difficult to execute and the results tend to be highly dependent on the prevailing natural conditions.

Since China does not have a dedicated biosafety law, the Ministry of Agriculture has overall enforcement responsibility when it comes to safety issues - with breaches punished at relatively low fines reaching up to $\$ 10,000$. Huang urges that more resources should be devoted to agricultural management by the government if the GM rice is to be commercialized, as the cost of management will be "minimal compared with the benefits of GM rice.”

Xun Zi, Beijing 